\title{
A Pyrazolo[3,4-d]pyrimidine Compound Reduces Cell Viability and Induces Apoptosis in Different Hematological Malignancies
}

\begin{abstract}
Ilaria Laurenzana ${ }^{1 *}$, Antonella Caivano', Francesco La Rocca', Stefania Trino', Luciana De Luca', Francesca D'Alessio², Silvia Schenone ${ }^{3}$, Geppino Falco ${ }^{4}$, Maurizio Botta ${ }^{5}$, Luigi Del Vecchio ${ }^{2,6+}$ and Pellegrino Musto ${ }^{7 \dagger}$
\end{abstract}

\begin{abstract}
' Laboratory of Preclinical and Translational Research, IRCCS - Referral Cancer Center of Basilicata (CROB), Rionero in Vulture, Potenza, Italy, ${ }^{2}$ Biotecnologie Avanzate s.c.a.r.l., CEINGE, Napoli, Italy, ${ }^{3}$ Department of Pharmacy, University of Genoa, Genoa, Italy, ${ }^{4}$ Department of Biology, University of Naples Federico II, Naples, Italy, ${ }^{5}$ Department of Biotechnology, Chemistry and Pharmacy, University of Siena, Siena, Italy, ${ }^{6}$ Department of Molecular Medicine and Medical Biotechnologies, University of Naples Federico II, Naples, Italy, ${ }^{7}$ Scientific Direction, IRCCS - Referral Cancer Center of Basilicata (CROB), Rionero in Vulture, Potenza, Italy
\end{abstract}

\section{OPEN ACCESS}

Edited by:

Daniele Tibullo,

University of Catania, Italy

Reviewed by:

Vincenzo Bramanti,

Azienda Ospedaliera Ospedali Riuniti

Villa Sofia Cervello, Italy

Giuseppe Alberto Palumbo, Azienda Ospedaliero - Universitaria "Policlinico - Vittorio Emanuele", Italy

*Correspondence:

Ilaria Laurenzana

ilaria.laurenzana@crob.it

†These authors have contributed equally to this work.

Specialty section:

This article was submitted to Experimental Pharmacology and Drug Discovery,

a section of the journal Frontiers in Pharmacology

Received: 30 September 2016 Accepted: 20 October 2016

Published: 07 November 2016

Citation:

Laurenzana I, Caivano A, La Rocca F, Trino S, De Luca L, D'Alessio F, Schenone S, Falco G,

Botta $M$, Del Vecchio $L$ and Musto P (2016)

A Pyrazolo[3,4-d]pyrimidine Compound Reduces Cell Viability and Induces Apoptosis in Different

Hematological Malignancies.

Front. Pharmacol. 7:416.

doi: 10.3389/fphar.2016.00416
Molecular targeted therapies are based upon drugs acting on tumors by interfering with specific targets involved in growth and spread of cancer. Many targeted therapies were approved by Food and Drug Administration as standard treatment, others were introduced into preclinical or clinical studies on hematological malignancies (HMs). The development of drug-resistance in some HMs and the lack of effective treatments in other ones emphasized the need for searching new molecular targets and therapeutic agents. The aim of this study was to evaluate the effects of $4 c$ pyrazolo[3,4- $d]$ pyrimidine compound, a Src inhibitor, on lymphoid and myeloid neoplasms. Here, we demonstrated its ability to reduce cell viability, induce apoptosis and cell cycle arrest in lymphoid cell lines such as Jurkat, SKMM1, Derl-2/7, and myeloid cell lines, such as Jurl-MK1. Moreover, we reported a high expression of a Src kinase, Fyn, in these cell lines compared to healthy subjects. This study was a starting point to investigate 4c pyrazolo[3,4-d]pyrimidine compound as a drug for $\mathrm{HMs}$ and Src kinases as its potential molecular targets.

Keywords: targeted therapies, Src kinase inhibitor, pyrazolo[3, 4- $d]$ pyrimidine compound, Fyn tyrosine kinase, hematological malignancies

\section{INTRODUTION}

Targeted cancer therapies are "drugs" designed to interfere with specific molecules necessary for tumor growth and progression. These agents are broadly classified in monoclonal antibodies and small molecules. The first are generally directed against antigens expressed on neoplastic cell surface, the second are usually designed to interfere with the enzymatic activity of the target protein. A primary goal of these kind of therapies is to fight cancer cells with more precision while to do less damage to normal cells.

The approval of imatinib mesylate for the treatment of chronic myeloid leukemia (CML) and its high success rate supported the extensive efforts to develop novel molecularly targeted therapies for hematologic malignancies (Cierpicki and Grembecka, 2015). On the other hand, the development of drug-resistance in some hematological tumors, for example in CML (An et al., 2010), and the lack of effective treatments in other ones (Martelli et al., 2012; Yang and Lin, 2015; Zinzani et al., 2015), addressed researchers to the study of new molecular targets and innovative therapeutic agents. 
A lot of new compounds have been synthesized, investigated, and introduced into pre-clinical and clinical studies in hematological malignancies (HMs; Korycka-Wołowiec et al., 2015). The majority of small molecule block activity of protein kinases, including FMS-like tyrosine kinase 3 (FLT3; Levis, 2013; Plawny and Rie, 2014), Aurora kinase (Garcia-Manero et al., 2015), JAK1/2 (Pinilla-Ibarz et al., 2016), Akt, mTOR (Cierpicki and Grembecka, 2015) and Src kinases (Roskoski, 2015b).

The Src family protein tyrosine kinases (SFKs) are nonreceptor intracellular kinases known to have diverse and important regulatory roles in both normal hematopoiesis and leukemogenesis. There are eight members of this family in mammals and they are structurally related, except for the unique domain: Src, Lyn, Hck, Fyn, Yes, Blk, Fgr, and Lck (Ku et al., 2015). SFKs represent appealing targets for cancer therapy because of their aberrant activation in many human cancer types and their key role in controlling several processes, such as proliferation, apoptosis, migration, and angiogenesis, whose deregulation underlies cancer development and progression (Yeatman, 2004).

Recently we synthesized new pyrazolo[3,4- $d]$ pyrimidine library of SFKs inhibitors, which entered in ATP binding site and showed antiproliferative and pro-apoptotic action in several tumor types such as CML and in Burkitt lymphoma (Schenone et al., 2010; Cozzi et al., 2012; Radi et al., 2013; Tintori et al., 2013). Moreover, we demonstrated that $4 \mathrm{c}$ pyrazolo[3,4- $d]$ pyrimidine compound was able to reduce cell viability, induce apoptosis and cell cycle arrest in a rare natural killer (NK) cell leukemia and in CML. In particular, it reduced phosphorylation of Fyn kinase in these neoplasms (Tintori et al., 2015; Laurenzana et al., 2016).

Fyn kinase is able to interact with several proteins and participates in different cellular pathways, both in physiological and pathological situations. It has been demonstrated that it is involved in the regulation of T-cell development and activation, factor and cytokine receptor signaling, cell-cell adhesion, integrin-mediated signaling, ion channel function, platelet activation, $\mathrm{T}$ - and $\mathrm{B}$-cell receptor signaling, axon guidance, mitosis, differentiation of NK cells (Palacios and Weiss, 2004; Salmond et al., 2009; Saito et al., 2010).

The aim of this study was to analyze the effects of $4 \mathrm{c}$ compound on viability of cell lines derived from different lymphoid and myeloid neoplasms and to report Fyn expression analysis in these tumors compared to healthy subjects.

\section{MATERIALS AND METHODS}

\section{Cell Lines and Chemical}

Peripheral blood samples were obtained from healthy donors (HDs). The study was approved by the Ethics Committee of IRCCS-CROB (Prot. 3725; 07/02/2008) and all subjects gave informed consent according to the Declaration of Helsinki. Peripheral blood mononuclear cells from HDs (HD-PBMCs) were isolated by Ficoll-hypaque gradient separation.

Both human lymphoid and myeloid cell lines were purchased from Leibniz-Institut DSMZ - Deutsche Sammlung von Mikroorganismen und Zellkulturen $\mathrm{GmbH}$ or from American
Type Culture Collection and cultured as follows. Jurkat (acute T cell leukemia), Derl-2 and Derl-7 (T cell lymphoma), NALM6 and BV173 (acute lymphoblastic leukemia), Jurl-MK1 (CML), NB4 and HL-60 (acute promyelocytic leukemia), Kasumi-1 (acute myeloid leukemia) cell lines were cultured in RPMI 1640 (Gibco, Life technologies, Carlsbad, CA, USA) supplemented with $20 \%$ fetal bovine serum (FBS, Gibco) and $1 \%$ of penicillinstreptomycin (pen/strep, Gibco). For Derl-2 and Derl-7, $20 \mathrm{ng} / \mathrm{ml}$ interleukin-2 (IL-2, Miltenyi Biotec, Auburn, CA, USA) was added at the previous indicated medium. OCI-AML3 cell line (acute myeloid leukemia) was cultured in Dulbecco's Modified Eagle Medium (DMEM, Gibco) supplemented with $20 \%$ FBS, $1 \%$ of pen/strep. SKMM1 cells (multiple myeloma) were cultured in Iscove's Modified Dulbecco's Medium (IMDM, Gibco) supplemented with 10\% FBS, $1 \%$ of pen/strep. All cell lines were maintained in incubator at $37^{\circ} \mathrm{C}$ and $5 \% \mathrm{CO}_{2}$.

4c pyrazolo[3,4- $d]$ pyrimidine compound, given by Lead Discovery Siena s.r.l. (patent: WO2016066755), was dissolved in dimethyl sulfoxide (DMSO, Sigma-Aldrich, St Louis, MO, USA) and diluted in FBS for cell treatments.

\section{Western Blotting (WB) Analysis}

Cells were lysed as previously reported (Trino et al., 2016). Sixty micrograms was subjected to sodium dodecyl sulfate polyacrylamide gel electrophoresis on a $10 \%$ gel under reducing conditions and then electrotransferred onto a polyvinylidene difluoride membranes using Trans Blot Turbo Transfer System (BioRad, Hercules, CA, USA). Membranes were probed with primary antibodies directed against Fyn and $\beta$-actin (Cell Signaling, Beverly, MA, USA), then incubated with secondary antibody (horseradish peroxidase-conjugated goat anti-mouse or anti-rabbit; Cell Signaling). Immune complexes were detected by ECL chemiluminescence system (Bio-Rad Laboratories), as recommended by the manufacturer. Densitometric analysis was performed using Bio-Rad Image Lab 4.1 software. The intensity of bands of all proteins was normalized to the $\beta$-actin signal.

\section{Cell Viability}

All cell lines were seeded into 96-well plates $\left(3 \times 10^{4}\right.$ cells $\left./ 100 \mu \mathrm{l}\right)$ and incubated with $4 \mathrm{c}$ compound at increasing concentrations $(1,5,10,15 \mu \mathrm{M})$. HD-PBMCs were incubated with $15 \mu \mathrm{M}$ of $4 \mathrm{c}$ compound. Treatment was carried out for 24, 48, and 72 h. Cells treated with DMSO vehicle were used as control. Cell viability was determined using the CellTiter 96 Aqueous One Solution assay kit (MTS, Promega, Madison, WI, USA). The optical density was measured at $492 \mathrm{~nm}$. Cellular viability was calculated as percentage of viable cells compared with control. All experiments were conducted in triplicate. $\mathrm{EC}_{50}$ values were obtained by GraphPad Prism (GraphPad Prism, San Diego, CA, USA).

\section{Functional Tests}

Cells were seeded at $3 \times 10^{5}$ cells $/ \mathrm{ml}$ cell density. Jurkat were treated with $2 \mu \mathrm{M}$ of $4 \mathrm{c}$ compound for 24,48 , and $72 \mathrm{~h}$; Derl-2 and Derl-7 with $4 \mu \mathrm{M}$ of $4 \mathrm{c}$ compound for $72 \mathrm{~h}$; while Jurl-MK1 with $1 \mu \mathrm{M}$ of $4 \mathrm{c}$ compound for $72 \mathrm{~h}$. All cell lines were incubated 
with DMSO vehicle as control. After $4 \mathrm{c}$ compound treatment cells were used in:

\section{Apoptosis Assay}

Apoptosis was evaluated by cytometric analysis of Annexin $\mathrm{V}$ and Propidium Iodide (PI)-stained cells using fluorescein isothiocyanate (FITC) Annexin V Apoptosis Detection kit I (BD) as previously reported (De Luca et al., 2016). Cells were acquired using FACSCalibur flow cytometer and analyzed by CellQuest Pro software (BD). Single positive for Annexin V and double positive for Annexin $\mathrm{V}$ and PI cells were interpreted as signs of early and late phases of apoptosis, respectively.

\section{Cell Cycle Analysis}

After treatment cells were fixed in cold ethanol $70 \%$ for $1 \mathrm{~h}$, then labeled with PI/RNase staining solution for $30 \mathrm{~min}$. Samples were acquired by FACSCalibur (BD). Data were analyzed by ModFit LT Software (Verity Software House).

\section{Statistical Analysis}

Statistical significance was determined using a paired $t$-test by GraphPad Prism. All error bars represent standard deviation (SD) of the mean. A $P$-value $\leq 0.05$ was accepted as statistically significant.

\section{RESULTS}

\section{4c Pyrazolo[3,4- $d$ ]pyrimidine Compound Reduced Cell Viability in Hematological Malignancies}

We treated 3 HD-PBMCs, 6 lymphoid and 5 myeloid cell lines (Table 1) with 4 c pyrazolo[3-4,d]pyrimidine compound or with DMSO vehicle control at increasing concentrations $(1-15 \mu \mathrm{M})$ from 24 to 72 h to verify its effect on cell viability.

First of all, we observed that $4 \mathrm{c}$ compound had negligible effect on HD-PBMCs at $15 \mu \mathrm{M}$ in a time course, from 24 to $72 \mathrm{~h}$ (Figure 1A). In the context of lymphoid malignancies (Figure 1B), Jurkat, SKMM1 and Derl-2 cell lines showed a wide reduction of cell viability (about $-50 \%$ ) already at $5 \mu \mathrm{M}$ and it increased at higher concentrations of $4 \mathrm{c}$ compound, reaching a reduction of cell viability of $60-70 \%$ at $10 \mu \mathrm{M}$. This effect was observed at $24 \mathrm{~h}$ and remained constant at other time points. Derl-7 and BV-173 showed a dose-dependent viability reduction after treatment with $4 \mathrm{c}$ compound with the higher effect at 48 and $72 \mathrm{~h},-25$ and $-60 \%$ at $15 \mu \mathrm{M}$, respectively. On NALM-6 cell line, we observed a reduction of viability of $40 \%$ at $15 \mu \mathrm{M}$ of $4 \mathrm{c}$ compound at all time points.

In the context of myeloid malignancies (Figure 1C), Jurl-MK1 and NB-4 showed a dose-dependent reduction of viability after $4 \mathrm{c}$ compound treatment, especially at 48 and $72 \mathrm{~h}$.

HL-60 and OCI-AML3 showed 20 and 30\% reduction of cell viability, respectively, after $15 \mu \mathrm{M} 4 \mathrm{c}$ treatment at all time points. Kasumi-1 showed a decrease of viability at increasing concentration of $4 \mathrm{c}$ compound at all time points; the reduction of $50 \%$ was observed at $15 \mu \mathrm{M}$ at 48 and $72 \mathrm{~h}$.
TABLE 1 | Hematological malignancies (HM) cell lines analyzed.

\begin{tabular}{lll}
\hline & Cell lines & Disease \\
\hline Lymphoid Neoplasms & Jurkat & Acute T cell leukemia \\
SKMM1 & Multiple myeloma \\
& Derl-2 & T cell lymphoma \\
Derl-7 & T cell lymphoma \\
BV-173 & Acute lymphoblastic leukemia \\
NALM-6 & Acute lymphoblastic leukemia \\
Jurl-MK1 & Chronic myeloid leukemia \\
NB-4 & Acute promyelocytic leukemia \\
HL-60 & Acute promyelocytic leukemia \\
OCl-AML3 & Acute myeloid leukemia \\
Kasumi-1 & Acute myeloid leukemia
\end{tabular}

We calculated $4 \mathrm{c}$ compound $\mathrm{EC}_{50}$ values for all cell lines at 24, 48, and $72 \mathrm{~h}$ (Table 2). For lymphoid neoplasms, Jurkat cells showed $\mathrm{EC}_{50}$ around $4 \mu \mathrm{M}$ at 24, 48, and $72 \mathrm{~h}$; SKMM1showed $\mathrm{EC}_{50}=7.7 \mu \mathrm{M}$ at $24 \mathrm{~h}$ which increased at 48 and $72 \mathrm{~h}$; Derl2, Derl-7 and BV-173 showed a decrease of $\mathrm{EC}_{50}$ values over time. For NALM-6 EC 50 value was much greater than the highest concentration used. For myeloid malignancies, Jurl-MK1 showed $\mathrm{EC}_{50}>15 \mu \mathrm{M}$ at $24 \mathrm{~h}$ but it considerably decreased at $2.5 \mu \mathrm{M}$ at 48 and $72 \mathrm{~h}$. The same trend was observed in NB-4 cells, in which $\mathrm{EC}_{50}$ was $>15 \mu \mathrm{M}$ at $24 \mathrm{~h}$ and it decreased at 48 and $72 \mathrm{~h}$ at 7.2

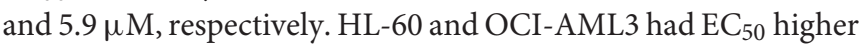
than $15 \mu \mathrm{M}$ at all time points. Kasumi-1 showed $\mathrm{EC}_{50}=15 \mu \mathrm{M}$ at 48 and $72 \mathrm{~h}$.

\section{4c Pyrazolo[3,4- $d$ ]pyrimidine Compound Increased Apoptosis in Jurkat, Derl-2, Derl-7, and Jurl-MK1 Cells}

To further investigate cell death mechanism induced after treatment, we performed apoptosis on Jurkat, Derl-2, Derl-7, and Jurl-MK1 cell lines by cytometric analysis of Annexin V/PI (Figure 2). Jurkat cells were treated with $2 \mu \mathrm{M}$ of $4 \mathrm{c}$ compound for 24,48 , and $72 \mathrm{~h}$. After treatment we observed a significant increase of apoptotic cells at all time points respect to their control, $34 \%$ at $24 \mathrm{~h}, 18 \%$ at $48 \mathrm{~h}$, and $27 \%$ at $72 \mathrm{~h}(p<0.01)$. The treatment with $4 \mu \mathrm{M}$ of $4 \mathrm{c}$ compound for $72 \mathrm{~h}$ on Derl-2 and Derl-7 induced an increased apoptosis respect to their control (40\% $p<0.05$ and 23\% $p<0.01$, respectively). Jurl-MK1 cells, after incubation with $1 \mu \mathrm{M}$ of $4 \mathrm{c}$ compound for $72 \mathrm{~h}$, showed an increased apoptosis rate respect to control $(18 \% ; p<0.05)$.

\section{4c Pyrazolo[3,4- $d]$ pyrimidine Compound Induced Cell Cycle Arrest in Jurkat, Derl-2, Derl-7, and Jurl-MK1 Cells}

We also performed cell cycle analysis on Jurkat, Derl-2, Derl-7, and Jurl-MK1 cell lines by cytometric analysis of PI (Figure 3). Jurkat were treated with $2 \mu \mathrm{M}$ of $4 \mathrm{c}$ compound for 24,48 , and $72 \mathrm{~h}$; Derl-2 and Derl-7 with $4 \mu \mathrm{M}$ of $4 \mathrm{c}$ at for $72 \mathrm{~h}$; while Jurl-MK1 with $1 \mu \mathrm{M}$ of $4 \mathrm{c}$ compound for $72 \mathrm{~h}$. Jurkat showed cell cycle arrest in G0/G1 phase in all time points, especially at $24 \mathrm{~h}$, respect to control. Derl-2 displayed a strong arrest in 

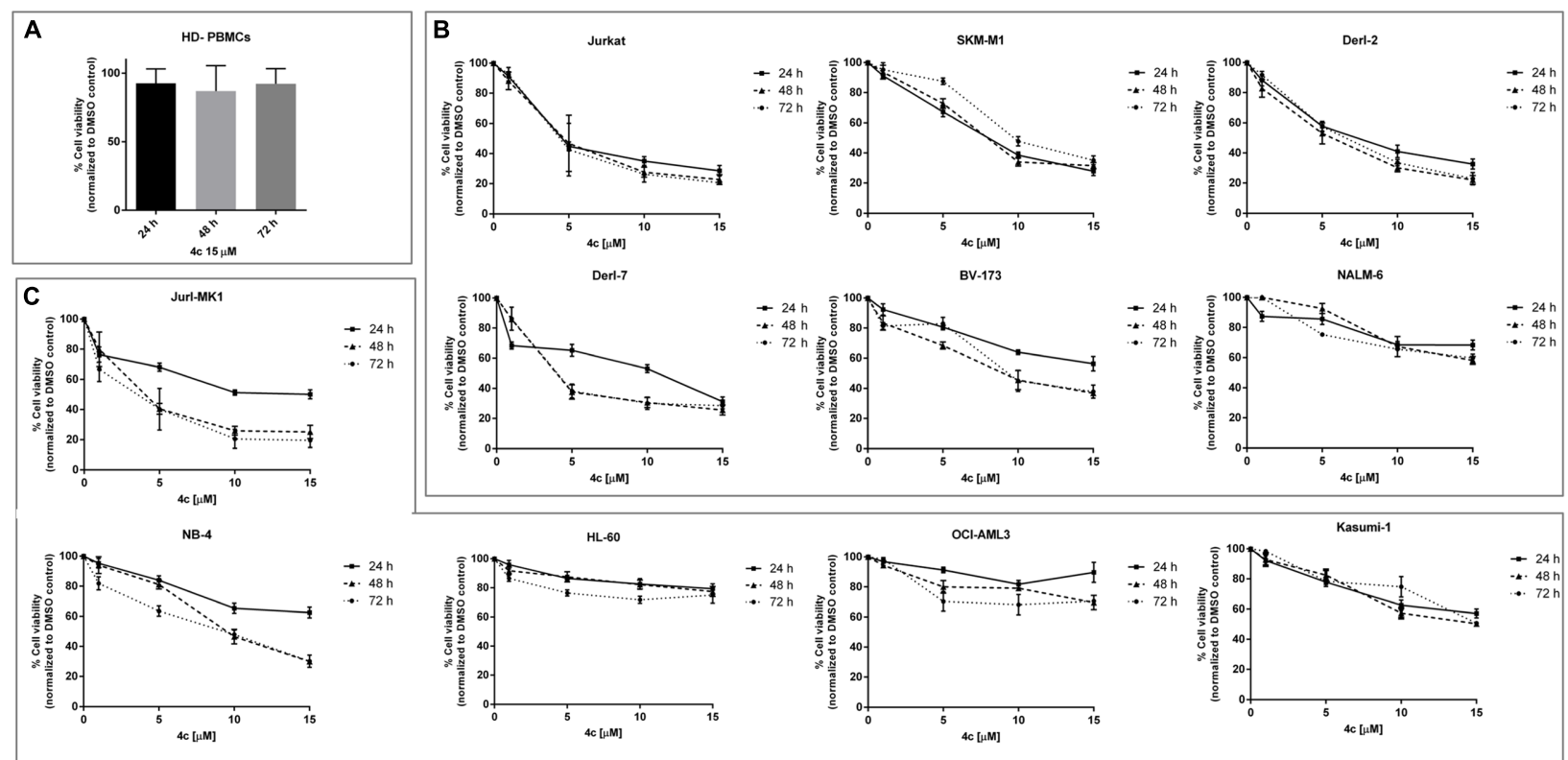

FIGURE 1 | Cell viability assay after 4c compound treatment in hematological malignancies. Viability of three healthy donors-peripheral blood mononuclear cells (HD-PBMCs) (A), six lymphoid (B), and five myeloid (C) cell lines was evaluated by MTS assay after treatment with $4 \mathrm{c}$ compound at different concentration (1, $5,10$, and $15 \mu \mathrm{M})$ for 24,48 , and $72 \mathrm{~h}$. Results are expressed as percent of cell viability normalized to DMSO-treated control cells. The bar-graphs represent mean with SD from three independent experiments.

TABLE 2 | $\mathrm{EC}_{50}$ values calculated in Healthy donors-peripheral blood mononuclear cells (HD-PBMCs) and in both lymphoid and myeloid cell lines after $4 \mathrm{c}$ compound treatment.

\begin{tabular}{|c|c|c|c|c|}
\hline & \multirow[t]{2}{*}{ Cells } & \multicolumn{3}{|c|}{$\mathrm{EC}_{50}[\mu \mathrm{M}]$} \\
\hline & & $24 \mathrm{~h}$ & $48 h$ & $72 \mathrm{~h}$ \\
\hline & HD-PBMCs & $>15$ & $>15$ & $>15$ \\
\hline \multirow[t]{6}{*}{ Lymphoid Neoplasms } & Jurkat & 4.6 & 4 & 3.8 \\
\hline & SKMM1 & 7.7 & 8.11 & 10.8 \\
\hline & Derl-2 & 7.5 & 5.9 & 6.2 \\
\hline & Derl-7 & 12.3 & 4.7 & 4.7 \\
\hline & BV-173 & $>15$ & 6.6 & 7.15 \\
\hline & NALM-6 & $>15$ & $>15$ & $>15$ \\
\hline \multirow[t]{5}{*}{ Myeloid Neoplasms } & Jurl-MK1 & $>15$ & 2.5 & 2.4 \\
\hline & NB-4 & $>15$ & 7.2 & 5.9 \\
\hline & HL-60 & $>15$ & $>15$ & $>15$ \\
\hline & OCl-AML3 & $>15$ & $>15$ & $>15$ \\
\hline & Kasumi-1 & $>15$ & 15 & 15 \\
\hline
\end{tabular}

G0/G1 phase, whereas Derl-7 manifested a negligible effect on cell cycle after treatment, respect to control. Jurl-MK1 showed a small increase of G0/G1 phase and a larger raise of percent of cells in $\mathrm{S}$ phase.

\section{Fyn Is Over-Expressed in Hematological Malignancies}

We analyzed Fyn protein expression in 3 HD-PBMCs, in lymphoid and myeloid cell lines by WB analysis. Fyn is over-expressed in lymphoid cell lines respect to HD-PBMCs; in particular, SKMM1 showed the major amount of protein, following by NALM-6, Derl-7, Jurkat, Derl-2, and BV-173. Also all myeloid Jurl-MK1, NB-4, OCI-AML3, and Kasumi-1 cells presented higher Fyn protein expression (Figure 4).

\section{DISCUSSION}

"Molecular targeted therapies" are used in the treatment of many cancers as first-line therapy (Neul et al., 2016). The first tyrosine kinase inhibitor (TKI) approved for the treatment of CML was imatinib mesylate (Cierpicki and Grembecka, 2015). Since then, over 3000 novel agents inhibiting diverse protein kinases are currently being explored preclinically and, at present, more than 130 novel TKIs are being evaluated in oncological clinical trials (Neul et al., 2016).

Recent studies on tumor pathobiology in hematological and solid cancers have revealed that heterogeneity is the major cause of poor drug efficacy and response duration (Visvader, 2011; McGranahan and Swanton, 2015; Belizário et al., 2016). Moreover, cancer cells that respond to particularly therapeutic treatment can rapidly adapt and develop drugresistance changing their signaling pathways (Luo et al., 2009; Carragher et al., 2012; McGranahan and Swanton, 2015; Belizário et al., 2016). At this point comes the need to screen new molecular targets and innovative therapeutic agents.

Protein kinases, including SFKs, are the most attractive target structures. They are key players in signal transduction networks mediating fundamental cellular processes such as 
Laurenzana et al.

Pyrazolo[3,4-d]pyrimidine Effect in Hematological Malignancies

Jurkat
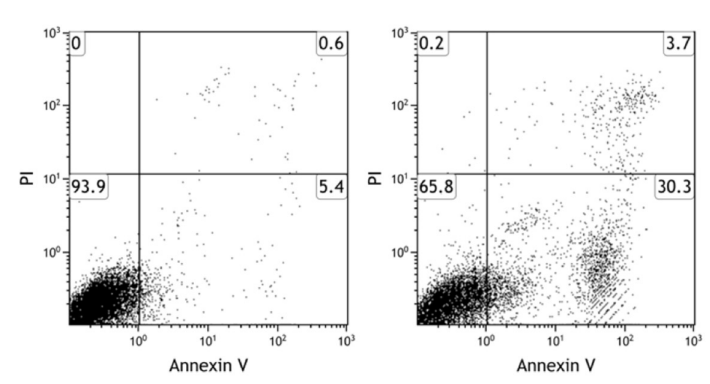

Derl-2
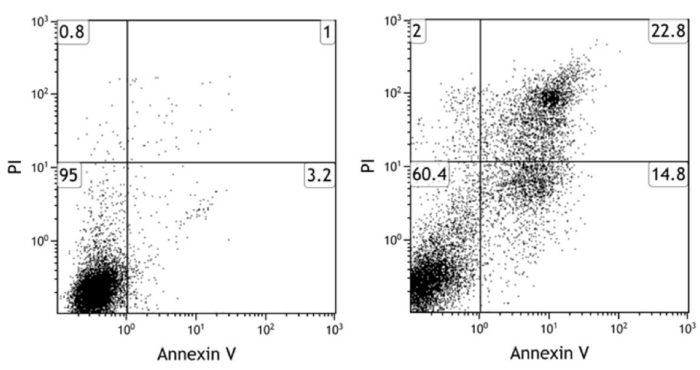

Derl-7
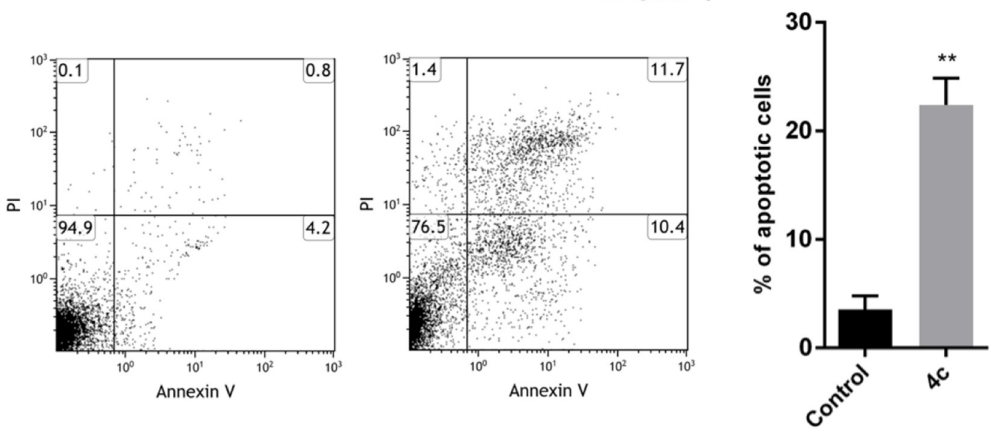

Jurl-MK1
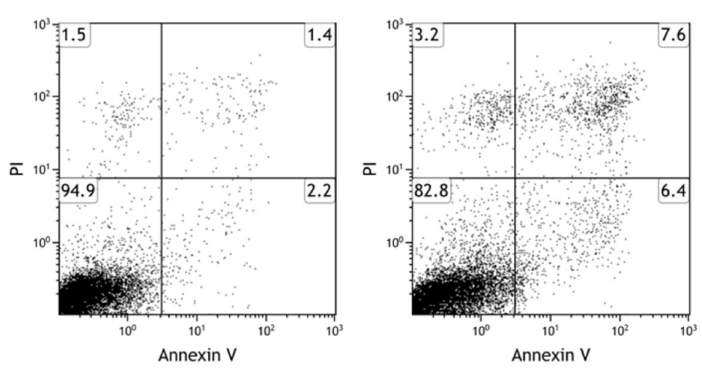

FIGURE 2 | Apoptosis analysis in hematological malignancies after Ac compound treatment. Apoptosis was evaluated by flow cytometer in Jurkat cell line after Ac compound or DMSO vehicle treatment at $2 \mu \mathrm{M}$ for 24, 48, and $72 \mathrm{~h}$; in Derl-2 and Derl-7 after treatment at $4 \mu \mathrm{M}$ for $72 \mathrm{~h}$; in Jurl-MK1 after treatment at $1 \mu \mathrm{M}$ for $72 \mathrm{~h}$. Dot plots show a single representative experiment, the bar-graphs represent mean with SD from three independent experiments. $*$ and ${ }^{* *}$ indicated a $P$-value minor than 0.05 and 0.01 , respectively.

Frontiers in Pharmacology | www.frontiersin.org

5

November 2016 | Volume 7 | Article 416 


\section{Jurkat}
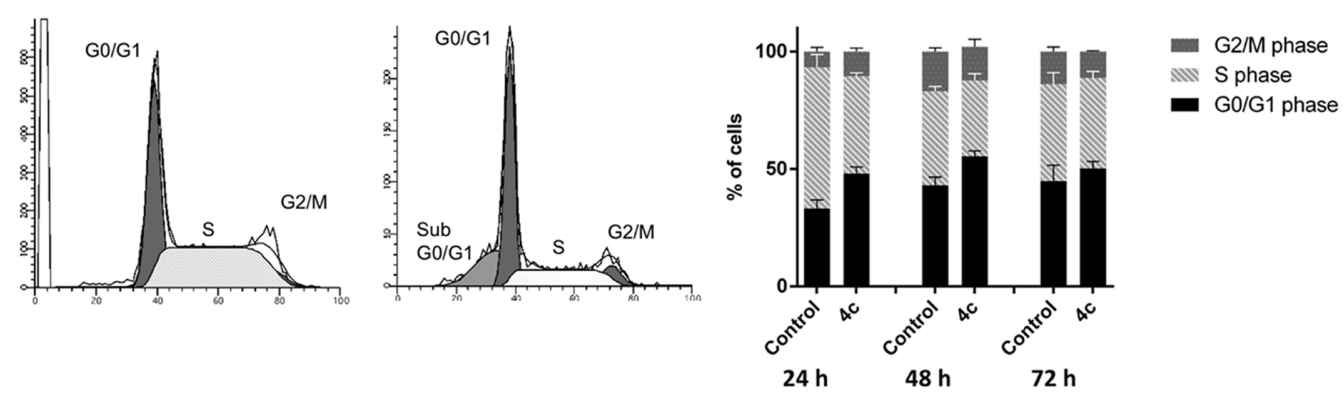

Derl-2
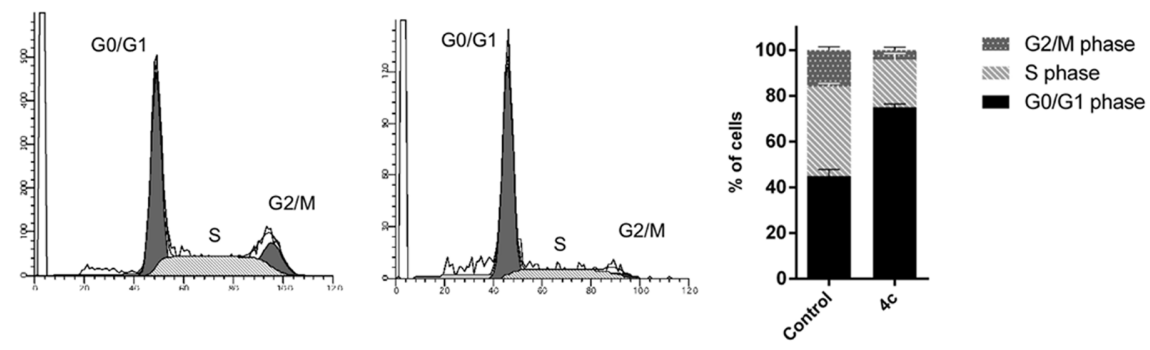

Derl-7
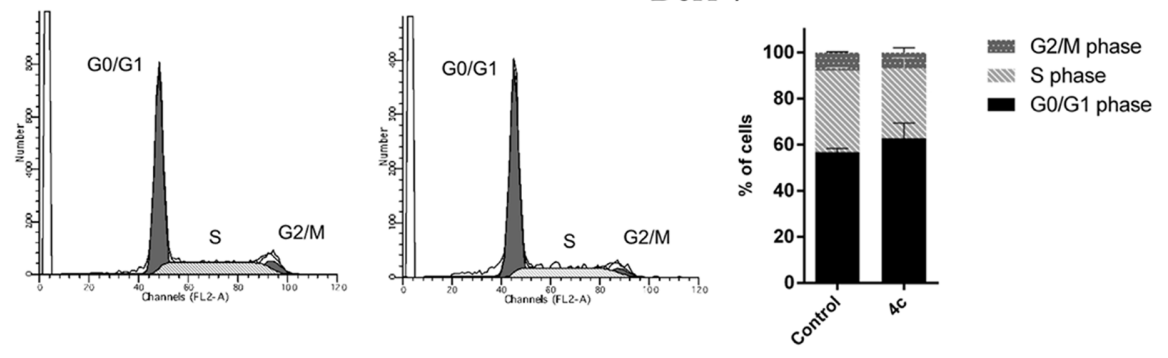

\section{Jurl-MK1}
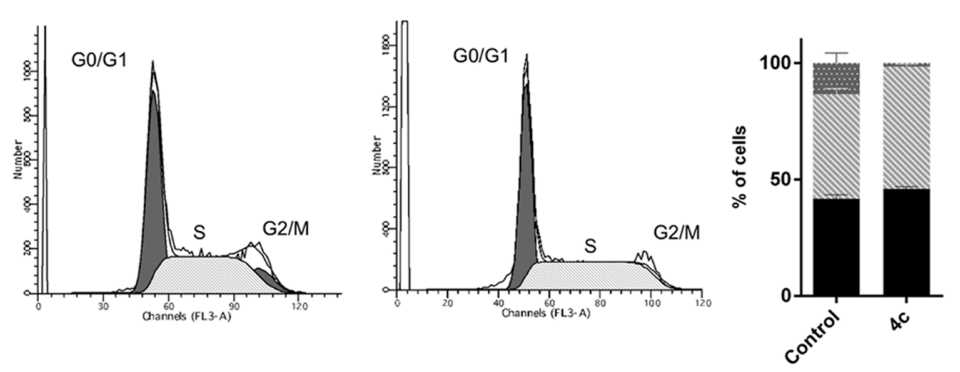

G2/M phase

Niv S phase

- G0/G1 phase

FIGURE 3 | Cell cycle analysis in hematological malignancies after $\mathbf{4 c}$ compound treatment. Cell cycle analysis was evaluated by flow cytometer in Jurkat cell line after 4c compound or DMSO vehicle treatment at $2 \mu \mathrm{M}$ for 24, 48, and $72 \mathrm{~h}$; in Derl-2 and Derl-7 after treatment at $4 \mu \mathrm{M}$ for $72 \mathrm{~h}$; in Jurl-MK1 after treatment at $1 \mu \mathrm{M}$ for $72 \mathrm{~h}$. Histogram plots show a single representative experiment, the bar-graphs represent mean with SD from three independent experiments.

cell differentiation, proliferation, apoptosis, transcription, metabolism, and intercellular communication. During the past 15 years, was emerged that many cancers originated from dysregulation of their signaling pathways (Manning et al., 2002; Levitzki, 2013; Rask-Andersen et al., 2014; Roskoski, 2015a) and drug development has shifted toward small molecules that specifically block them.
In this context, our group developed a library of pyrazolo[3,4- $d]$ pyrimidine compounds which have the ability to inhibit some of Src kinases by entering in the ATP binding site. In particular, we have previously demonstrated that $4 \mathrm{c}$ pyrazolo[3,4- $d]$ pyrimidine compound, is able to inhibit Fyn kinase and to induce apoptosis in cells derived from NK leukemia and from CML (Tintori et al., 2015; Laurenzana et al., 2016). 

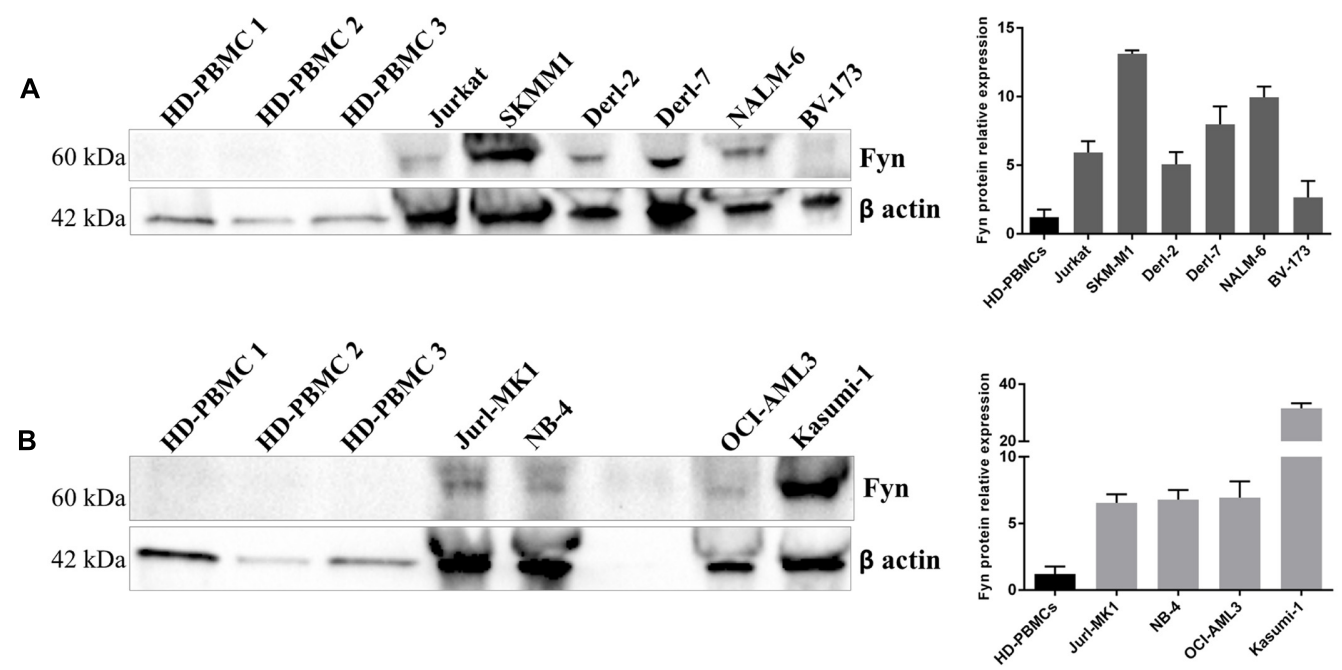

FIGURE 4 | Fyn expression in different hematological malignant cells. Western Blotting (WB) analysis of Fyn levels in 3 HD-PBMCs compared to lymphoid cell lines (A) and in three HD-PBMCs compared to myeloid cell lines (B). Quantification of Fyn protein levels was normalized with $\beta$-actin bands. The bar-graphs represent mean with SD from three independent experiments.

In this study, we demonstrated, for the first time, the cytotoxic effect of $4 \mathrm{c}$ compound on HMs compared with HD-PBMCs.

First, we investigated the response of cell viability to $4 \mathrm{c}$ compound treatment. We have recently demonstrated that $4 \mathrm{c}$ compound, up to $10 \mu \mathrm{M}$, had no effect on HD-PBMCs cell viability at 24, 48, and $72 \mathrm{~h}$ (Laurenzana et al., 2016). In this study, we confirmed these data and observed that also $15 \mu \mathrm{M}$ of $4 \mathrm{c}$ compound had no effect on viability of HD-PBMCs at all time points.

Interestingly, Jurkat, SKMM1, Derl-2, Derl-7, and BV-173 showed a dose-dependent reduction of cell viability and their $\mathrm{EC}_{50}$ values were in a range of $3-10 \mu \mathrm{M}$ at all time points. Derl-2 and Derl-7 were established from the same patient with hepatosplenic $\gamma \delta \mathrm{T}$ cell lymphoma, but they showed a different phenotype: Derl-2 was TcR $\gamma \delta^{+}$, while Derl-7 was TcR $\gamma \delta^{-}$(Di Noto et al., 2001). Derl-2, closer to T cells, showed a lower $\mathrm{EC}_{50}$ at $24 \mathrm{~h}$. Within lymphoid cell lines, NALM-6 showed a lower response to $4 \mathrm{c}$ treatment and a reduction of $50 \%$ of cell viability at higher concentrations respect to other cells. BV-173 and NALM-6 derived both from acute lymphoblastic leukemia but showed different response to $4 \mathrm{c}$ compound, probably due to the clinical and biological heterogeneity of this neoplasm. BV-173, for example, expressed Philadelphia $(\mathrm{Ph})$ chromosome, lacking instead in NALM-6. In the context of myeloid cell lines, we observed an $\mathrm{EC}_{50}$ achievement at concentration $\leq 15 \mu \mathrm{M}$ at 48 and $72 \mathrm{~h}$ for Jurl-MK1, NB-4, and Kasumi-1 cell lines. Jurl-MK1 response could be comparable to lymphoid BV-173 cells probably due to the presence of $\mathrm{Ph}$ chromosome in both cell lines.

In general, lymphoid cells seemed to respond better than myeloid ones. In agreement with our data, a lot of recent studies showed that the use of TKIs, especially against Btk, Syk, and Lyn, is a promising new strategy for targeted treatment of B-cell lymphoid malignancies (Robak and Robak, 2012).
Furthermore, these data on Jurl-MK1 confirmed our previously results obtained in K562 CML cell line (Tintori et al., 2015).

We decided to study in deep the viability reduction in Jurkat, Derl-2, Derl-7, and Jurl-MK1 cell lines and we demonstrated that $4 \mathrm{c}$ compound induced apoptosis and cell cycle arrest.

Recent studies showed that other small molecules induced cell viability reduction and apoptosis in cell lines used in our study. For example, Bucur et al. (2015) synthesized a small molecule that binds caspase 8 and enhances its activation when combined with TRAIL inducing apoptosis in Jurkat cells. Furthermore, Lin et al. (2010) demonstrated that SMI-4a, a small molecule inhibitor of Pim kinases, kill a wide range of both myeloid and lymphoid cell lines with precursor T-cell lymphoblastic leukemia/lymphoma being highly sensitive.

Since we previously observed, by in vitro enzymatic assay, that $4 \mathrm{c}$ compound inhibited different Src kinases, in particular Fyn with $\mathrm{IC}_{50}=0.07 \mu \mathrm{M}$ (Tintori et al., 2015), we verified the presence of Fyn protein in our HM cell lines. Interestingly, we observed that its expression is higher and variable in all cell lines compared to HD-PBMCs.

Fyn, a member of SFKs, has diverse molecular functions, including regulation of cell growth, survival, adhesion, cytoskeletal remodeling, motility, axon guidance, synaptic function, platelet activation, and $\mathrm{T}$ cell receptor signaling. It is involved in various aspects of the pathogenesis of different types of cancers as well as drug resistance (Elias and Ditzel, 2015) so it could be a potential therapeutic target.

In a rare NK leukemia, we demonstrated that antiproliferative activity of $4 \mathrm{c}$ compound was due to Fyn kinase inhibition (Laurenzana et al., 2016). Recently, Palomero et al. (2014) demonstrated that dasatinib, a multikinase inhibitor which blocks ABL1 and SRC kinases, induced dose dependent inhibition of FYN phosphorylation. 
Our preliminary data indicated Fyn as a potential target of $4 \mathrm{c}$ compound but cannot be excluded that $4 \mathrm{c}$ compound might also act on other Src kinases activated in neoplastic cells. Other experiments are needed to evaluate this hypothesis.

In summary, in this study we demonstrated that $4 \mathrm{c}$ pyrazolo[3,4- $d]$ pyrimidine compound had cytotoxic effect by inducing a reduction of cell viability and a increased apoptosis in different cell lines derived from HMs. Finally, we observed that $4 \mathrm{c}$ compound potential target, Fyn kinase, is over-expressed in all cell lines used. But others experiments are necessary in this fields, because this study represents a starting point to better investigate the effect of $4 c$ pyrazolo $[3,4-d]$ pyrimidine compound and the role of Src kinases in HMs.

\section{AUTHOR CONTRIBUTIONS}

All authors participated to the conception of the study; IL, designed the work, planned and performed experiments,

\section{REFERENCES}

An, X., Tiwari, A. K., Sun, Y., Ding, P. R., Ashby, C. R. Jr., and Chen, Z. S. (2010). BCR-ABL tyrosine kinase inhibitors in the treatment of Philadelphia chromosome positive chronic myeloid leukemia: a review. Leuk. Res. 34, 1255-1268. doi: 10.1016/j.leukres.2010.04.016

Belizário, J. E., Sangiuliano, B. A., Perez-Sosa, M., Neyra, J. M., and Moreira, D. F. (2016). Using pharmacogenomic databases for discovering patient-target genes and small molecule candidates to cancer therapy. Front. Pharmacol 7:312. doi: 10.3389/fphar.2016.00312

Bucur, O., Gaidos, G., Yatawara, A., Pennarun, B., Rupasinghe, C., Roux, J., et al. (2015). A novel caspase 8 selective small molecule potentiates TRAIL-induced cell death. Sci Rep. 5:9893. doi: 10.1038/srep09893

Carragher, N. O., Brunton, V. G., and Frame, M. C. (2012). Combining imaging and pathway profiling: an alternative approach to cancer drug discovery. Drug Discov. Today 17, 203-214. doi: 10.1016/j.drudis.2012.02.002

Cierpicki, T., and Grembecka, J. (2015). Targeting protein-protein interactions in hematologic malignancies: still a challenge or a great opportunity for future therapies? Immunol. Rev. 263, 279-301. doi: 10.1111/imr. 12244

Cozzi, M., Giorgi, F., Marcelli, E., Pentimalli, F., Forte, I. M., Schenone, S., et al. (2012). Antitumor activity of new pyrazolo[3,4-d]pyrimidine SRC kinase inhibitors in Burkitt lymphoma cell lines and its enhancement by WEE1 inhibition. Cell Cycle 11, 1029-1039. doi: 10.4161/cc.11.5.19519

De Luca, L., Trino, S., Laurenzana, I., Simeon, V., Calice, G., Raimondo, S., et al. (2016). MiRNAs and piRNAs from bone marrow mesenchymal stem cell extracellular vesicles induce cell survival and inhibit cell differentiation of cord blood hematopoietic stem cells: a new insight in transplantation. Oncotarget 7, 6676-6692. doi: 10.18632/oncotarget.6791

Di Noto, R., Pane, F., Camera, A., Luciano, L., Barone, M., Lo Pardo, C., et al. (2001). Characterization of two novel cell lines, DERL-2 (CD56+/CD3+/Tcry5+) and DERL-7 (CD56+/CD3-/TCRgammadelta-), derived from a single patient with CD56+ non-Hodgkin's lymphoma. Leukemia 15, 1641-1649.

Elias, D., and Ditzel, H. J. (2015). Fyn is an important molecule in cancer pathogenesis and drug resistance. Pharmacol. Res. 100, 250-254. doi: 10.1016/j.phrs.2015.08.010

Garcia-Manero, G., Tibes, R., Kadia, T., Kantarjian, H., Arellano, M., Knight, E. A., et al. (2015). Phase 1 dose escalation trial of ilorasertib, a dual Aurora/VEGF receptor kinase inhibitor, in patients with hematologic malignancies. Invest. New Drugs 33, 870-880. doi: 10.1007/s10637-015-0242-6

Korycka-Wołowiec, A., Wołowiec, D., and Robak, T. (2015). Pharmacodynamic considerations of small molecule targeted therapy for treating B-cell performed flow cytometry analysis, analyzed data, drafted paper; AC, designed the work, planned experiments, analyzed data, drafted paper; FL, ST, LD, FD, performed experiments and analyzed data; SS and MB, designed and synthesized chemical compound; GF improved writing paper; LD and PM, designed the work, improved writing paper; all authors approved the final version of the manuscript.

\section{FUNDING}

This work was supported by Italian Ministry of Health, Current Research Founds for IRCCS, CUP E66J12000230001.

\section{ACKNOWLEDGMENT}

The authors acknowledge Lead Discovery Siena s.r.l. that holds intellectual property of patent [WO2016066755].

malignancies in the elderly. Expert Opin. Drug Metab. Toxicol. 11, 1371-1391. doi: 10.1517/17425255.2015.1055246

Ku, M., Wall, M., MacKinnon, R. N., Walkley, C. R., Purton, L. E., Tam, C., et al. (2015). Src family kinases and their role in hematological malignancies. Leuk. Lymphoma 56, 577-586. doi: 10.3109/10428194.2014.907897

Laurenzana, I., Caivano, A., Trino, S., De Luca, L., La Rocca, F., Simeon, V., et al. (2016). A Pyrazolo[3,4-d]pyrimidine compound inhibits fyn phosphorylation and induces apoptosis in natural killer cell leukemia. Oncotarget doi: 10.18632/oncotarget.11496 [Epub ahead of print].

Levis, M. (2013). FLT3 mutations in acute myeloid leukemia: what is the best approach in 2013? Hematol. Am. Soc. Hematol. Educ. Program 2013, 220-226. doi: 10.1182/asheducation-2013.1.220

Levitzki, A. (2013). Tyrosine kinase inhibitors: views of selectivity, sensitivity, and clinical performance. Annu. Rev. Pharmacol. Toxicol. 53, 161-185. doi: 10.1146/annurev-pharmtox-011112-140341

Lin, Y. W., Beharry, Z. M., Hill, E. G., Song, J. H., Wang, W., Xia, Z., et al. (2010). A small molecule inhibitor of Pim protein kinases blocks the growth of precursor T-cell lymphoblastic leukemia/lymphoma. Blood 115, 824-833. doi: 10.1182/blood-2009-07-233445

Luo, J., Solimini, N. L., and Elledge, S. J. (2009). Principles of cancer therapy: oncogene and non-oncogene addiction. Cell 136, 823-837. doi: 10.1016/j.cell.2009.02.024

Manning, G., Whyte, D. B., Martinez, R., Hunter, T., and Sudarsanam, S. (2002). The protein kinase complement of the human genome. Science 298, 1912-1934. doi: $10.1126 /$ science. 1075762

Martelli, A. M., Chiarini, F., Evangelisti, C., Ognibene, A., Bressanin, D., Billi, A. M., et al. (2012). Targeting the liver kinase B1/AMP-activated protein kinase pathway as a therapeutic strategy for hematological malignancies. Expert Opin. Ther. Targets 16, 729-742. doi: 10.1517/14728222.2012. 694869

McGranahan, N., and Swanton, C. (2015). Biological and therapeutic impact of intratumor heterogeneity in cancer evolution. Cancer Cell 27, 15-26. doi: 10.1016/j.ccell.2014.12.001

Neul, C., Schaeffeler, E., Sparreboom, A., Laufer, S., Schwab, M., and Nies, A. T. (2016). Impact of membrane drug transporters on resistance to small-molecule tyrosine kinase inhibitors. Trends Pharmacol. Sci. doi: 10.1016/j.tips.2016.08.003 [Epub ahead of print].

Palacios, E. H., and Weiss, A. (2004). Function of the Src-family kinases, Lck and Fyn, in T-cell development and activation. Oncogene 23, 7990-8000.

Palomero, T., Couronné, L., Khiabanian, H., Kim, M. Y., Ambesi-Impiombato, A., Perez-Garcia, A., et al. (2014). Recurrent mutations in epigenetic regulators, RHOA and FYN kinase in peripheral T cell lymphomas. Nat. Genet. 46, 166-170. doi: 10.1038/ng.2873 
Pinilla-Ibarz, J., Sweet, K. L., Corrales-Yepez, G. M., and Komrokji, R. S. (2016). Role of tyrosine-kinase inhibitors in myeloproliferative neoplasms: comparative lessons learned. Onco Targets Ther. 9, 4937-4957. doi: 10.2147/OTT.S102504

Plawny, L., and Rie, F. (2014). Emerging new anticancer biological therapies in 2013 (haematological malignancies). Curr. Opin. Oncol. 26, 363-370. doi: 10.1097/CCO.0000000000000079

Radi, M., Tintori, C., Musumeci, F., Brullo, C., Zamperini, C., Dreassi, E., et al. (2013). Design, synthesis, and biological evaluation of pyrazolo[3,4d]pyrimidines active in vivo on the Bcr-Abl T315I mutant. J. Med. Chem. 56, 5382-5394. doi: 10.1021/jm400233w

Rask-Andersen, M., Zhang, J., Fabbro, D., and Schiöth, H. B. (2014). Advances in kinase targeting: current clinical use and clinical trials. Trends Pharmacol. Sci. 35, 604-620. doi: 10.1016/j.tips.2014.09.007

Robak, T., and Robak, E. (2012). Tyrosine kinase inhibitors as potential drugs for B-cell lymphoid malignancies and autoimmune disorders. Expert Opin. Investig. Drugs 21, 921-947. doi: 10.1517/13543784.2012.685650

Roskoski, R. Jr. (2015a). A historical overview of protein kinases and their targeted small molecule inhibitors. Pharmacol. Res. 100, 1-23. doi: 10.1016/j.phrs.2015.07.010

Roskoski, R. Jr. (2015b). Src protein-tyrosine kinase structure, mechanism, and small molecule inhibitors. Pharmacol. Res. 94, 9-25. doi: 10.1016/j.phrs.2015.01.003

Saito, Y. D., Jensen, A. R., Salgia, R., and Posadas, E. M. (2010). Fyn: a novel molecular target in cancer. Cancer 116, 1629-1637. doi: 10.1002/cncr.24879

Salmond, R. J., Filby, A., Qureshi, I., Caserta, S., and Zamoyska, R. (2009). T-cell receptor proximal signaling via the Src-family kinases, Lck and Fyn, influences T-cell activation, differentiation, and tolerance. Immunol. Rev. 228, 9-22. doi: 10.1111/j.1600-065X.2008.00745.x

Schenone, S., Brullo, C., Musumeci, F., and Botta, M. (2010). Novel dual Src/Abl inhibitors for hematologic and solid malignancies. Expert Opin. Investig. Drugs 19, 931-945. doi: 10.1517/13543784.2010.499898

Tintori, C., La Sala, G., Vignaroli, G., Botta, L., Fallacara, A. L., Falchi, F., et al. (2015). Studies on the ATP binding site of fyn kinase for the identification of new inhibitors and their evaluation as potential agents against tauopathies and tumors. J. Med. Chem. 58, 4590-4609. doi: 10.1021/acs.jmedchem.5b00140

Tintori, C., Laurenzana, I., La Rocca, F., Falchi, F., Carraro, F., Ruiz, A., et al. (2013). Identification of Hck inhibitors as hits for the development of antileukemia and anti-HIV agents. ChemMedChem. 8, 1353-1360. doi: 10.1002/cmdc.201300204

Trino, S., Iacobucci, I., Erriquez, D., Laurenzana, I., De Luca, L., Ferrari, A., et al. (2016). Targeting the p53-MDM2 interaction by the small-molecule MDM2 antagonist Nutlin-3a: a new challenged target therapy in adult Philadelphia positive acute lymphoblastic leukemia patients. Oncotarget 7, 12951-12961. doi: 10.18632/oncotarget.7339

Visvader, J. E. (2011). Cells of origin in cancer. Nature 469, 314-322. doi: 10.1038 /nature09781

Yang, W. C., and Lin, S. F. (2015). Mechanisms of drug resistance in relapse and refractory multiple myeloma. Biomed. Res. Int. 2015:341430. doi: $10.1155 / 2015 / 341430$

Yeatman, T. J. (2004). A reinassance for SRC. Nat. Rev. Cancer 4, 470-480. doi: $10.1038 / \mathrm{nrcl} 366$

Zinzani, P. L., Pellegrini, C., Broccoli, A., Gandolfi, L., Stefoni, V., Casadei, B., et al. (2015). Fludarabine-Mitoxantrone-Rituximab regimen in untreated indolent non-follicular non-Hodgkin's lymphoma: experience on 143 patients. Hematol. Oncol. 33, 141-146. doi: 10.1002/hon.2151

Conflict of Interest Statement: The authors declare that the research was conducted in the absence of any commercial or financial relationships that could be construed as a potential conflict of interest.

Copyright (C) 2016 Laurenzana, Caivano, La Rocca, Trino, De Luca, D’Alessio, Schenone, Falco, Botta, Del Vecchio and Musto. This is an open-access article distributed under the terms of the Creative Commons Attribution License (CC BY). The use, distribution or reproduction in other forums is permitted, provided the original author(s) or licensor are credited and that the original publication in this journal is cited, in accordance with accepted academic practice. No use, distribution or reproduction is permitted which does not comply with these terms. 